\title{
Patterns of Malaria Morbidity and Environmental Conditions in the Otamiri River Basin of Nigeria: A Case Study of Ihiagwa Community, Imo State ${ }^{+}$
}

\author{
Chiamaka Uwalaka ${ }^{1, *}$, Okwuoma C. Abanobi ${ }^{2}$ and Babatunde Adewale ${ }^{1}$ \\ 1 Public Health and Epidemiology Department, Nigerian Institute of Medical Research, Yaba, \\ Lagos P.M.B 2013, Nigeria; badewale@hotmail.com \\ 2 Department of Public Health, Federal University of Technology, Owerri, Imo State P.M.B 1526, Nigeria; \\ professorabanobi@yahoo.com \\ * Correspondence: amakaone2006@yahoo.com; Tel.: +234-703-648-0023 \\ † Presented at the 5th African Conference on Emerging Infectious Diseases, Abuja, Nigeria, 7-9 August 2019. \\ Published: 24 March 2020
}

\begin{abstract}
Background: Malaria is invariably one of the most perplexing problems of public health importance all over the world affecting mainly tropical and sub-tropical regions of the world. The study determined the influence of environmental conditions on malaria morbidity. Methods: The study was descriptive in design. Structured household questionnaire with three sections was administered to heads of households and on the spot assessment of the environment was carried out. Twelve households from each of the 8 villages that consist of Ihiagwa community were randomly selected. Data was analyzed using IBM SPSS Statistics for Windows version 20.0, Armonk, NY, USA. Results: Findings from the study revealed that $47.9 \%$ of the 96 household heads had attained tertiary education although $45.85 \%$ of them were self-employed and only $8.3 \%$ were civil servants. Majority (59.4\%) had a family size of less than 4 while $40.6 \%$ had a family size above 4. Among the study participants, $77.3 \%$ confirmed having suffered malaria in the last three months though $44.6 \%$ of them were diagnosed by their family members and majority $(52.7 \%)$ were unable to carry out their duties for about 7 days. Generally, the people lived in a clean environment, $97.8 \%$ of them claimed that they cleared their bushes in their environment weekly. Majority (57\%) lived in an environment without stagnant water, poorly draining gutters and exposed septic tanks. There was no statistically significant relationship between environmental conditions and reported malaria cases $(P=1.0)$. Conclusion: This is in contrast with some other studies however the result does not affirm that malaria morbidity has no relationship with the environment of people rather a need for certain factors to be controlled.
\end{abstract}

Keywords: malaria; morbidity; environment

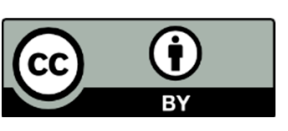

(C) 2020 by the authors. Licensee MDPI, Basel, Switzerland. This article is an open access article distributed under the terms and conditions of the Creative Commons Attribution (CC BY) license (http://creativecommons.org/licenses/by/4.0/). 